\title{
Determination of Secondary Nanostructure of Model Membrane from Local Fishes for Application in Pharmaceutical Field
}

\author{
M. KumpugdeE-Vollrath* \\ Beuth Hochschule für Technik Berlin - University of Applied Sciences, Faculty of Mathematics-Physics-Chemistry, \\ Pharmaceutical and Chemical Engineering, Luxemburger Str. 10, D-13353 Berlin, Germany
}

As it is difficult to obtain human stratum corneum for testing the pharmacological effect of the drugs, many researchers have tried to find alternative membrane for this purpose, instead of the human skin. Many animal skins e.g. pig, reptile, or fish skin seem to be suitable for this purpose. Therefore this project will provide more details to help understand more deeply the structure of these alternative skins. This project is focused on the fish skin because such skin can be easily found in Germany. Two different techniques i.e. small and wide angle X-ray scattering (SWAXS) and differential scanning calorimetry (DSC) have been applied for characterization of some local fish skins. The results showed that different skins (i.e. human stratum corneum, pig, shed snake, and fish) showed small differences in SWAXS patterns as well as in DSC thermograms. The drug paracetamol and the surfactant sodium lauryl sulphate can penetrate into the fish skins and they can affect a rearrangement of the inner structure which contains different lipids and proteins. The data are in agreement with those obtained for the shed snake skins in our previous study.

DOI: 10.12693/APhysPolA.127.1240

PACS: 87

\section{Introduction}

There is a considerable interest for the use of alternative model membrane for in vitro pharmaceutical applications. However, it is particularly difficult to obtain human skin for in vitro experiments and it is therefore important to have alternative membranes which mimic human skin (Stratum corneum). It is mentioned in the literature [1-3] that different membranes can be used likewise, as for example pig, reptile, or fish skin. Our previous work showed that the local snake's shed skin from Python molurus molurus was the most effective model membrane for this purpose, because it can be easily obtained from the reptile shop without any cost. However, further model membranes e.g. from fishes may also be of interest. Some researchers $[2-3]$ have mentioned the possibility to make use of them. The advantages of the fish skins are that they can be obtained at the supermarket or fish shop. We do not need to wait for the shedding process, as it is in case of snakes. However, the fish skins should be freshly prepared and used directly without storing. In order to understand the secondary nanostructure of model membrane, the SWAXS and DSC techniques were applied.

\section{Materials and methods}

Different local fish skins i.e. European plaice (Pleuronectes platessa), Atlantic salmon (Salmo salar),

* e-mail: vollrath@beuth-hochschule.de
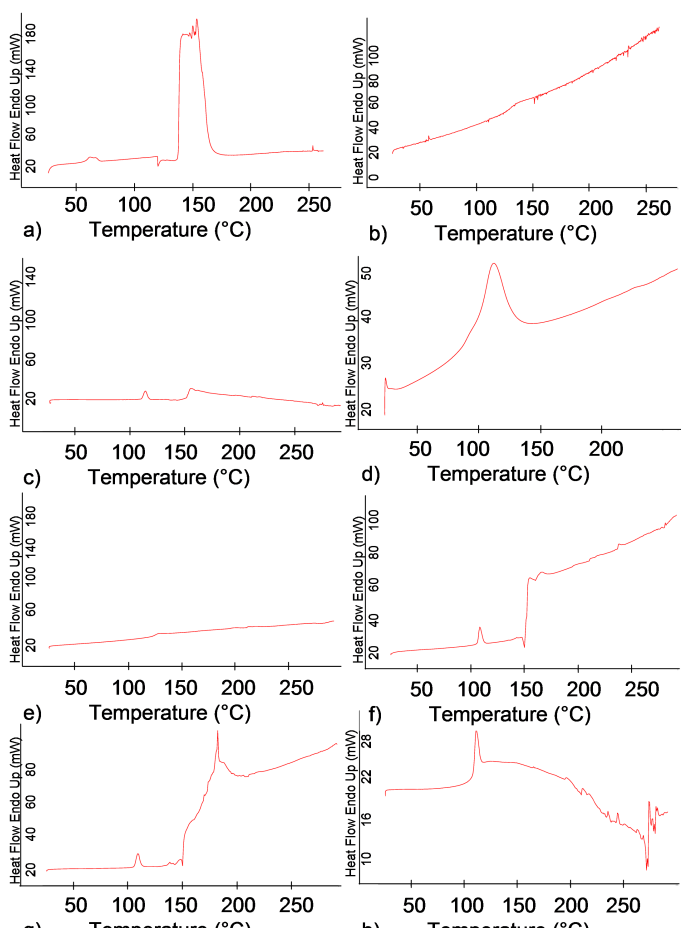

g) Temperature $\left({ }^{\circ} \mathrm{C}\right)$

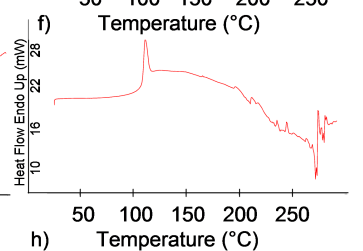

Fig. 1. Examples of some DSC-thermograms of untreated fish skins and those treated with a drug: (a) gilt-head bream, wet skin, no treatment, (b) gilt-head bream, dry skin, no treatment, (c) gilt-head bream skin, treated with paracetamol, (d) trout skin, scale part no treatment, (e) salmon skin treated with ibuprofen, (f) salmon skin treated with paracetamol, (g) plaice skin black side treated with paracetamol, (h) plaice skin white side treated with paracetamol. 
Atlantic cod (Gadus morhua), Trout (Salmo trutta), Gilthead bream (Sparus aurata) from Germany were used in this project. Different substances (paracetamol, ibuprofen, sodium lauryl sulphate-SLS, Tween80) were studied to understand the effect on the model skins. The DSC measurements were performed using Perkin Elmer 7 (USA). The sample of each skin of about $10-20 \mathrm{mg}$ was put into an aluminum pan which afterwards was sealed and measured under nitrogen gas in the temperature range of $30-300{ }^{\circ} \mathrm{C}$ at the scanning rate of $10{ }^{\circ} \mathrm{C} / \mathrm{min}$. The SWAXS measurements were performed at the beamline B1, HASYLAB, DESY, Hamburg at the X-ray energy of $14 \mathrm{keV}$. Further details of methods can be found in our previous article [1].

TABLE I

DSC results showing the melting peaks as mean and standard deviation values $\left({ }^{\circ} \mathrm{C}\right)$ of the pure drug or of fish skins after treatment with the respective drug $(n=1 \div 5)$.

\begin{tabular}{|c|c|c|}
\hline $\begin{array}{l}\text { Fish Skin } \\
(+ \text { drug })\end{array}$ & $\begin{array}{c}T_{\text {Mean }}, \\
{\left[{ }^{\circ} \mathrm{C}\right]}\end{array}$ & $\begin{array}{l}T_{\mathrm{SD}}, \\
{\left[{ }^{\circ} \mathrm{C}\right]}\end{array}$ \\
\hline Paracetamol & 170.80 & 0.79 \\
\hline Ibuprofen & 76.61 & 0.50 \\
\hline \multicolumn{3}{|c|}{ Gilt-head bream } \\
\hline wet & $61.52 \& 153.34$ & \\
\hline dry & 137.25 & 7.65 \\
\hline + Paracetamol & $116.24 \& 159.73$ & $1.51 \& 3.76$ \\
\hline \multicolumn{3}{|c|}{ Trout } \\
\hline wet & $51.27 \& 157.62$ & $1.15 \& 13.37$ \\
\hline dry & 126.28 & 3.01 \\
\hline scale & 118.83 & 6.56 \\
\hline +Paracetamol & $113.57 \& 170.24$ & $0.42 \& 3.86$ \\
\hline \multicolumn{3}{|c|}{ Atlantic cod } \\
\hline wet & $47.00 \& 135.03$ & \\
\hline dry & 122.61 & 0.90 \\
\hline +Paracetamol & $107.95 \& 161.42$ & $0.72 \& 14.52$ \\
\hline \multicolumn{3}{|c|}{ Atlantic salmon } \\
\hline wet & 49.79 & 0.45 \\
\hline dry & $58.70 \& 119.80$ & \\
\hline scale & $74.09 \& 114.79$ & \\
\hline +Paracetamol & $107.96 \& 167.05$ & $1.26 \& 2.12$ \\
\hline +Ibuprofen & $135.27 \& 169.15$ & $9.62 \& 4.66$ \\
\hline \multicolumn{3}{|c|}{ European plaice } \\
\hline black side wet & $49.80 \& 147.50$ & \\
\hline white side wet & $49.33 \& 150.52$ & \\
\hline black side dry & 132.13 & 0.35 \\
\hline white side dry & 130.62 & 0.96 \\
\hline black side+Paracet. & $109.18 \& 178.83$ & $0.42 \& 3.69$ \\
\hline white side+Paracet. & $111.11 \& 169.50$ & $0.41 \& 6.35$ \\
\hline
\end{tabular}

\section{Results and discussion}

The results of DSC measurements are demonstrated in Fig. 1. The DSC-thermograms show the melting points or re-crystallization process depending on skin or drug. Surprisingly the DSC-thermogram of the fish scale showed a good sharp peak (e.g. Fig. 1d), whereas the
TABLE II

SWAXS results for scattering vectors $Q$ of different skins and effect of surfactants. HSC - Human stratum corneum, PMM - Python molurus molurus.

\begin{tabular}{|c|c|c|c|c|}
\hline $\begin{array}{l}\text { Type of skin } \\
\text { (+ substances) }\end{array}$ & $\begin{array}{c}\text { Peak } 1 \\
{[1 / \AA]}\end{array}$ & $\begin{array}{c}\text { Peak } 2 \\
{[1 / \AA]}\end{array}$ & $\begin{array}{c}\text { Peak } 3 \\
{[1 / \AA]}\end{array}$ & $\begin{array}{c}\text { Peak } 4 \\
{[1 / \AA]}\end{array}$ \\
\hline HSC, dry & 0.186 & 0.658 & 1.520 & 1.690 \\
\hline Plaice black side, wet & - & 0.544 & 1.375 & 2.197 \\
\hline Plaice white side, wet & - & 0.544 & 1.389 & 2.190 \\
\hline Atlantic cod, wet & - & 0.544 & 1.396 & 2.240 \\
\hline Salmon, wet & 0.157 & 0.557 & 1.396 & 2.177 \\
\hline PMM, dry & 0.157 & 0.666 & 1.410 & 1.660 \\
\hline Pig ear, dry & 0.107 & 0.644 & 1.509 & - \\
\hline Pig abdomen, dry & 0.121 & 0.659 & 1.375 & 1.503 \\
\hline Gilt-head bream, wet & $0.265^{*}$ & 0.529 & 1.382 & 2.183 \\
\hline Trout, wet & - & 0.551 & 1.389 & 2.190 \\
\hline Salmon $+5 \%$ Tween 80 & 0.558 & 1.389 & 1.839 & 2.240 \\
\hline Salmon $+5 \%$ SLS & $0.150,0.565$ & 1.403 & - & 2.240 \\
\hline Salmon $+10 \%$ Tween 80 & 0.558 & 1.382 & - & 2.205 \\
\hline Atlantic cod $+5 \%$ Tween 80 & 0.565 & 1.389 & 1.847 & 2.283 \\
\hline Atlantic cod $+5 \%$ SLS & $0.329^{*}, 0.536$ & 1.453 & 1.839 & 2.219 \\
\hline Atlantic cod $+10 \%$ Tween 80 & 0.572 & 1.375 & 1.839 & 2.247 \\
\hline Salmon+Ethanol & 0.536 & 1.382 & - & 2.190 \\
\hline Atlantic cod+Ethanol & 0.543 & 1.389 & 1.832 & 2.226 \\
\hline Plaice white side, dry & $0.988^{*}$ & 1.389 & - & 2.219 \\
\hline Plaice black side, dry & 0.644 & 1.375 & - & 2.219 \\
\hline Salmon, dry & $0.966^{*}$ & 1.367 & 1.818 & 2.233 \\
\hline Pig abdomen $+5 \%$ SLS & $\begin{array}{c}0.164 \\
0.322^{*}, 0.487\end{array}$ & 1.446 & 1.524 & 1.997 \\
\hline Pig abdomen+Ethanol & 0.107 & 0.616 & 1.496 & - \\
\hline Pig abdomen $+5 \%$ Tween 80 & 0.107 & 0.623 & 1.510 & - \\
\hline $5 \%$ Tween 80 & 0.136 & - & - & - \\
\hline $5 \% \mathrm{SLS}$ & 1.178 & - & - & - \\
\hline
\end{tabular}

* Not comparable with other values.

whole skins showed many peaks (e.g. Fig. 1c, 1g). Table I shows that the wet fish skin did not produce reasonable DSC thermograms because of the effect of water from the samples. Therefore the skin samples were dried in a desiccator with an absorbing substance for at least overnight period. After application of the drying process the skins showed better DSC-curves. By comparing the melting peak of the pure drug (i.e. paracetamol or ibuprofen) and the skins treated with a drug, it can be deduced that the paracetamol drug can penetrate through all studied fish skins. However, tha secondary nanostructure of some fish skins has changed, which can be monitored by the reduction or the increase of melting peaks of the paracetamol drug. The SWAXS scattering patterns (Fig. 2) showed typical peaks at different scattering vectors $(Q)$. After comparison of the patterns of different skins i.e. human, pig, shed snake, or fish skins, small differences were detected. The effect of the tested surfactants or enhancers, i.e. SLS and Tween80, was also clearly seen. SLS can penetrate into the model fish skins but Tween 80 cannot. Some examples of SWAXS patterns are shown in Fig. 2 and the $Q$-values are summarized in Table II. 


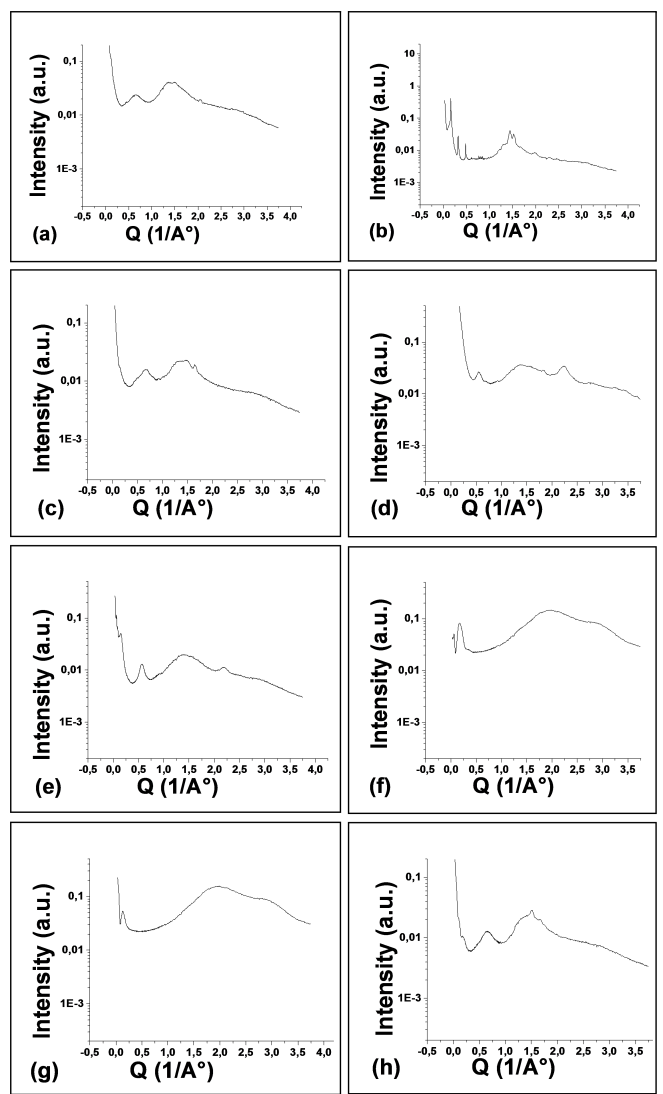

Fig. 2. SWAXS scattering patterns of different skins and effect of different substances: (a) pig abdomen skin, dry, no treatment, (b) pig abdomen skin treated with $5 \%$ SLS, (c) Python molurus molurus skin, dry, no treatment, (d) salmon skin treated with 5\% Tween 80 , (e) salmon skin treated with $5 \%$ SLS, (f) $5 \%$ SLS, (g) $5 \%$ Tween80, (h) human stratum corneum.

\section{Conclusions}

By combination of the DSC and SWAXS characterization techniques a deeper understanding of the secondary nanostructure of the model membrane from local fishes can be obtained. Though the fish skins showed small differences in comparison with the human startum corneum, pig or shed snake skins, the results showed that the fish skins may be suitable for application in pharmaceutical field with small limitations.

\section{Acknowledgments}

The author thanks Institut für Angewandte Forschung Berlin e.V. (IFAF), Europäischer Fonds für regionale Entwicklung (EFRE), European Regional Development Fund (ESF), Zentrales Innovationsprogramm Mittelstand (ZIM), as well as the Federal Ministry of Economics and Technology (BMWi) of Germany for the financial support; DESY, Beamline B1, Dr. U. Vainio for the SWAXS-measurements and analysis; Prof. Dr. H. Hungerbühler, Mr. E. Leo and Mr. R. Trummer for DSC-experiments.

\section{References}

[1] N. Wonglertnirant, T. Ngawhirunpat, M. Kumpugdee-Vollrath, Biol. Pharm. Bull. 35(4), 523 (2012).

[2] M. Masson, S.D. Sigfusson, T. Loftsson, Journal of Inclusion Phenomena and Macrocyclic Chemistry 44, 177 (2002).

[3] F. Konradsdottir, T. Loftsson, S.D. Sigfusson, Journal of Pharmacy and Pharmacology 61, 121 (2009). 